Aunque no vale la pena estudiar la importancia ni la aplicación de estos casos sin tener en cuenta todas las demás variantes, quisiera indicar aquí unos ejemplos de la utilidad de las identificaciones hechas. Todos los casos de textos de A ofrecen un terminus ad quem de 1580 , y quizá las variantes ayuden a fechar partes de A. La identificación de A, p. 564 , vs. $1-2$, con $\mathrm{P} / \mathrm{III} / \mathrm{xvI}$, vs. $1-2$, nos revela los modelos de Herrera (Garcilaso, Virgilio y Ovidio) y su intento estilístico en estos versos de P. Finalmente, un caso como la presencia de la palabra Conde en $\mathrm{B} / \mathrm{XIvIII}$ y su ausencia en $\mathrm{P} / \mathrm{II} / \mathbf{L X V I I}$ nos da una razón más para relacionar los textos $\mathrm{B}$ y $\mathrm{H}$ frente al texto $\mathrm{P}^{4}$.

A. David KossofF

Brown University.

\title{
¿CINCO VERSILLOS QUE NO SON DE GÓNGORA?
}

Entre los diversos poemas atribuidos a Góngora por R. FoulchéDelbosc y Millé y Giménez ${ }^{1}$ figuran cinco versillos contra Lope de Vega, no exentos de cierta gracia:

Dicen que ha hecho Lopico

contra mí versos adversos; mas si yo vuclvo mi pico, con el pico de mis versos a este Lopico lo-pico.

Pero esta quintilla figura a su vez en el ms. $3^{6} 57$ de la B. N. M., fol. 135 , atribuída a un "Juan Navarro de Cascante, poeta ridículo", con estas variantes:

\section{A LOPE DE VEGA}

Aunque tienc ese Lopico [contra mí] versos adversos, cuando yo extiendo mi pico, con el pico de mis versos a ese Lopico lo pico.

Claro está que esa sola mención no justificaría nada, pero es que junto a nuestro poemilla se copian otros muchos en los que se abusa de la misma técnica del jugueteo verbal, lo que prueba una misma mano. He aquí otro ejemplo:

\section{A Alarcón, poeta}

Con versos de corcovón

a Alarcón tanto le espanta

\footnotetext{
*Véase A. Costrr, Fernando de Herrera, Paris, 1908, pp. 192-194, donde habla de un fenómeno análogo de supresión en las variantes de $\mathrm{H}$ y $\mathrm{P}$.

1 Obras poeticas de don Luis de Cóngora, New York, 1921, t. 3. p. 42; Obras com. pletas de don Luis de Góngora, Madrid, 1932, p. 452. Véase en esta edición la nota de los hermanos Millé y Giménez, p. 1207.
} 
Pantaleón, que Alarcón,

que de un león no se espanta,

le espanta Pantaleón.

Finalmente, entre otros poemitas semejantes, pero esta vez anónimos, figura en el ms. 8252 de la B. N. M., fol. 68, con variantes que prueban una transmisión oral, nada rara en un poemita breve y deliciosamente irónico:

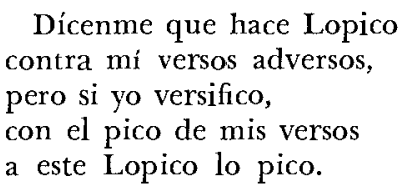

¿Serán de Góngora? Yo lo dudo mucho, puesto que de serlo tendríamos que atribuirle todos los que figuran como de ese desconocido Juan Navarro de Cascante, "poeta ridículo".

José Manuel Blecua

Zaragoza.

\section{EL AUTOR DE LA CANCIÓN "UFANO, ALEGRE, ALTIVO, ENAMORADO”}

En 1943 (RFE, 26, pp. 8o ss.) llamé la atención sobre el pequeño detalle de que el nombre de Mira de Amescua no figurase al frente de las mejores copias manuscritas de la célebre "Canción real a una mudanza" y que, en cambio, dos de los mejores mss. coincidiesen en señalar por autor a un Trevijano: "Canción real del Treuijano", rezaba un copia; al paso que en otra se leía: "Canción del Trebijano, caballero de Burgos", y hasta copiaba otra canción del mismo autor ${ }^{1}$. Mis diligencias por averiguar quién se escondía bajo ese nombre, que parecia seudónimo académico, no dieron ningún resultado hasta que en la Houghton Library de la Universidad de Harvard tuve ocasión de estudiar el ms. Span. 56 , copiado, quizá por el pintor Pacheco, suegro de Velázquez, en 1631, a juzgar por el título y el contenido. En los fols. 152-155 figuraba de nuevo la célebre canción con este encabezamiento: "Canción de don Joseph de Saravia, Secretario del Duque de Midina Sidonia, con nombre impuesto de Trevijano". Por fin quedaba aclarado un pequeño misterio. Todo lo demás era bastante sencillo.

En efecto, don José de Saravia fue en los años de 1628-16go, por lo menos, secretario del Duque de Medina Sidonia, pues figura como tal entre los amigos que elogian el Panegirico de Pedro Espinosa. Allí se dice que es "caballero de Santiago, señor de la villa de Eransus, secretario del Excelentísimo de Medina Sidonia, montero de cámara de Su Majestad"2. Y, conocido el dato de ser caballero de Santiago, nada

${ }^{1}$ Ms. 25o, fol. $678 \mathrm{v}^{\circ}$, de la Biblioteca Universitaria de Zaragoza, editado por mi con el título de Cancionero de 1628 (Madrid, 1945), y ms. 3913 de la B. N. M., fol. 11 .

${ }^{2}$ Obras de Pedro Espinosa, ed. de F. Rodriguez Marín, Madrid, 1909, p. 354. 